\title{
Nematophagous Resupinate Basidiomycetous Fungi
}

\author{
S. S. Tzean and J. Y. Liou
}

Department of Plant Pathology and Entomology, National Taiwan University, Taipei, Taiwan, 10617, Republic of China. This research was supported by grants from the National Science Council (NSC81-0409-B002-49) and the Ministry of Economic Affairs, Taiwan, R. O. C.

We thank S. H. Shiu and L. S. Hsieh for their valuable assistance; M. J. Tsai for the performance of the transmission electron microscopy; C. P. Lin for critical review of the article; C. R. Bergman, G. L. Barron, J. Ginns, and S. H. Wu for providing some of the fungal cultures, and J. S. Chen for providing some of the nematode species for this study. Special thanks are due to $\mathrm{S}$. H. Wu for the identification of Hyphoderma mucronatum.

Accepted for publication 4 June 1993.

\section{ABSTRACT}

Tzean, S. S., and Liou, J. Y. 1993. Nematophagous resupinate basidiomycetous fungi. Phytopathology 83:1015-1020.

Eighteen species of resupinate fungi belonging to Hyphoderma
(Corticiaceae) attacked and consumed nematodes by two different mecha-
nisms. Seven Hyphoderma spp. (H. baculorubrense, H. guttuliferum, H.
macronatum, H. praetermissum, H. puberum, H. rude, and H. tenue)
used adhesive stephanocysts to adhere to, capture, infect, and destroy
their prey, whereas 11 Hyphoderma spp. (H. albicans, H. amoenum, H.
heterocystidium, H. medioburiensis, H. mutatum, H. obtusiforme, H.
pallidum, H. populneum, H. radula, H. setigerum, and $H$. typhicola) lacked stephanocysts and destroy and consumed mycophagous nematodes after they ingested the fungal mycelium. Electron microscopy showed that the stephanocysts possess dolipore septa and are coated with fibrous mucilage, which thickens and becomes pad-shaped upon contact with the nematode's cuticle. Infection pegs, arising from a short protuberance, penetrate the host by a combination of mechanical and enzymatic activities. Profuse trophic hyphae break out of the nematode and form a new crop of stephanocysts.

Additional keywords: nematode host preference, parasites of nematodes, ultrastructural host-parasite interface.

Hohenbuehelia, a gilled fungus in the Pleurotiaceae (Agaricales, Hymenomycetes), is the teleomorphic state of form-genus Nematoctonus $(1,7)$ and is characterized by the ability to trap or infect nematodes by adhesive hourglass cells or adhesive conidia (8-11). At least 10 species of gilled fungi belonging to the genera Hohenbuehelia, Pleurotus, and Resupinatus can attack nematodes by adhesion or toxins $(2,27,28)$. Wood-decay fungi that use nutrients from their prey to supplement the limited nitrogen sources available in wood may play a significant role in some soil systems $(2,27,28)$. The occurrence of many carnivorous flowering plants, which capture insects in nitrogen-deficient environments such as acid bogs, may represent the same type of phenomenon (17).

Recently, we have shown that a putative Hyphoderma sp. (NP1) can capture nematodes by stephanocysts and infect and consume them (23). This finding contrasts with previous hypotheses that suggest that stephanocysts act as asexual spores, dispersal propagules (5), chlamydospores (22), or beneficial nutritional structures (16). Stephanocysts are unique structures present in the hymenium of some Hyphoderma spp. among the resupinate basidiomycetous fungi $(3-5,12,21)$. For the presumptive Hyphoderma sp. (NP1), however, only the stephanocysts and chlamydospores have been described. Therefore, the taxonomic status of this fungus remains unknown. The objective of the studies described here was to examine the possible nematophagous habit of Hyphoderma spp.

\section{MATERIALS AND METHODS}

Taxonomic authorities. For ease in reading the text, the taxonomic authorities for most species are shown only in the tables. Authorities are presented in the text only for those taxa not listed in the tables.

Fungal strains. The cultures of resupinate basidiomycetous fungi used in this study were obtained from six sources. A local collection of 181 fresh specimens, most of which belonged to the Corticiaceae or Stereaceae, represented one source. Sporocarps were collected from dead trees or fallen twigs of woody or herbacious plants in Wulai and Shitsu (Taipei County), Neiwan

1993 The American Phytopathological Society
(Hsinchu County), and Hsitou (Nantou County), Taiwan. Pieces of sporocarps with the hymenium were attached to the inside of the lids of polystyrene petri dishes over $3 \%$ water agar. Hyphae from basidiospores that had been discharged onto the agar and that had germinated were transferred to oatmeal agar (OMA) slants. A total of 57 isolates were obtained. The other five sources of isolates were: the National Museum of Natural Science, Taiwan (13 species of fungi from the Corticiaceae, including Efibula, Hyphoderma, Hyphodontia, Phanerochaete, Phlebia, Pulcherricium, and Resinicium); Ottawa Central Experimental Farms, Canada (an isolate of Hyphoderma tenue [DAOM 22985]); Osaka Institute of Fermentation, Japan (an isolate of Hyphoderma praetermissum [IFO 31346]); the U.S. Department of AgricultureForest Service, Forest Products Laboratory, Madison, WI (16 Hyphoderma spp.); and the Centraalbureau voor Schimmelcultures, Baarn, Netherlands (the remaining cultures of fungi in the Corticiaceae listed in Table 1).

Nematode-destroying capacity. To evaluate the nematodedestroying capacity of different isolates, a piece of agar containing juvenile and adult $(\sim 300)$ nematodes of an Aphelenchoides sp. cultured with an unidentified dematiaceous mycelia sterilia on OMA was placed near the margin of the colony of each putative nematophagous fungus on OMA. Usually within $10 \mathrm{~min}$, a large number of nematodes migrated into the mycelium of the test fungus. Sequential observations by light microscopy on the interactions were conducted after $5 \mathrm{~min}$ and up to $2 \mathrm{wk}$.

Host range and specificity. To determine the host range and specificity, 11 species of nematodes, including Aphelenchoides besseyi, Bursaphelenchus xylophilus, Hirschmanniella oryzae, Meloidogyne incognita, Helicotylenchus sp., Rotylenchulus sp., Trophorus sp., Xiphinema sp., free-living Plectus sp. and Rhabditis sp., and carnivorous Mononchus sp. were added to the colony of a putative Hyphoderma sp. (NP1) and examined as described above. An Aphelenchoides sp. was included as a positive check because it had been shown to be captured by the Hyphoderma sp. (NP1). The number of nematodes used in this test ranged from 10 to 300 , depending on the nematode species, and each experiment was repeated at least once. A. besseyi was collected from seeds of a rice crop exhibiting white tip symptoms in Pingtung County. B. Xyphilus, isolated from a wilted Luchuensis pine 
tree in Taipei County, was cultured with a sterile fungus. $M$. incognita, isolated from egg plants, was grown with mung bean seedlings in a growth pouch. $H$. oryzae was retrieved from the rhizosphere of paddy rice; Helicotylenchus $\mathrm{sp}$. and Rotylenchulus sp. were from soybean; and Trophurus sp., Mononchus sp., Plectus sp., and Rhabditis sp. were recovered from aerable soils by the Baermann funnel method (26). A population of Rhabditis sp. has been established on Nigon agar (26). Most of these nematodes were recovered from southern Taiwan between Decem-

TABLE 1. Evaluation of species of resupinate basidiomycetous fungi for the ability to infect or destroy Aphelenchoides spp.

\begin{tabular}{|c|c|c|}
\hline Fungus & Source ${ }^{\mathrm{a}}$ & Effect $^{b}$ \\
\hline Cylindrobasidium torrendii (Bres.) Hjortst. & Wu 911107-61 & $\mathrm{N}$ \\
\hline Efibula tropica $\mathrm{Wu}$ & Wu 901218 & $\mathrm{~N}$ \\
\hline Hyphoderma albicans (Pers.) Nakas. & USDA 3359 & $\mathrm{~T}$ \\
\hline H. amoenum (Burt) Donk & USDA 10282 & $\mathrm{~T}$ \\
\hline H. argillaceum (Bres.) Donk & CBS 250.73 & $\mathrm{~N}$ \\
\hline H. baculorubrense Gilbn. \& M. Blackwell & USDA 3127 & $\mathrm{C}$ \\
\hline H. clavigerum (Bres.) Donk & USDA 3134 & $\mathrm{~N}$ \\
\hline H. deviatum Lund. & USDA 3138 & $\mathrm{~N}$ \\
\hline H. fouquieriae Nakas. \& Gilbn. & USDA 3148 & $\mathrm{~N}$ \\
\hline H. guttuliferum (Karst.) Donk & USDA 3152 & $\mathrm{C}$ \\
\hline H. heterocystidium (Burt) Donk & USDA 3157 & $\mathrm{~T}$ \\
\hline H. leoninum Burdsall \& Nakas. & USDA 3163 & $\mathrm{~N}$ \\
\hline H. litschaueri (Burt) Erikss. \& Strid. & Wu $880804-10$ & $\mathrm{~N}$ \\
\hline H. medioburiensis (Burt) Donk & USDA 3176 & $\mathrm{~T}$ \\
\hline H. mucronatum (Furukawa) $\mathrm{Wu}$ & PPE 24 & $\mathrm{C}$ \\
\hline H. mutatum (Peck) Donk & CBS 290.36 & $\mathrm{~T}$ \\
\hline H. obtusiforme Erikss. \& Strid. & USDA 11564 & $\mathrm{~T}$ \\
\hline H. orphanellum (Buurd. \& Galz.) Donk & CBS 366.82 & $\mathrm{~N}$ \\
\hline H. pallidum (Bres.) Donk & CBS 708.84 & $\mathrm{~T}$ \\
\hline H. populneum (Peck) Donk & CBS 392.48 & $\mathrm{~T}$ \\
\hline H. praetermissum (Karst.) Erikss. \& Strid. & Wu $880801-18$ & $\mathrm{C}$ \\
\hline H. praetermissum (Karst.) Erikss. \& Strid. & IFO 31346 & $\mathrm{C}$ \\
\hline H. puberum (Fr.:Fr.) Wallr. & CBS 355.54 & $\mathrm{C}$ \\
\hline H. radula $(\mathrm{Fr}$.) Donk & CBS 472.72 & $\mathrm{~T}$ \\
\hline H. rimosum Burdsall \& Nakas. & USDA 3269 & $\mathrm{~N}$ \\
\hline H. rude (Bres.) Hjortst. \& Ryvarden & USDA 3288 & C \\
\hline H. setigerum (Fr.:Fr.) Donk & Wu $880701-33$ & $\mathrm{~T}$ \\
\hline H. subdefinitum Erikss. \& Strid. & USDA 10733 & $\mathrm{~N}$ \\
\hline H. tenue (Pat.) Donk & CBS 280.50 & $\mathrm{~N}$ \\
\hline H. tenue (Pat.) Donk & DAOM 22985 & $\mathrm{C}$ \\
\hline H. typhicola (Burt) Donk & USDA 11770 & $\mathrm{~T}$ \\
\hline Hyphodontia alutaria (Burt) J. Erikss. & CBS 397.62 & $\mathrm{~N}$ \\
\hline H. barba-jovis (Fr.) J. Erikss. & CBS 232.63 & $\mathrm{~N}$ \\
\hline H. crustosa (Pers.:Fr.) J. Erikss. & CBS 398.62 & $\mathrm{~N}$ \\
\hline H. formosana Wu \& Burds. & Wu $880819-27$ & $\mathrm{~N}$ \\
\hline H. papillosa (Fr.:Fr.) J. Erikss. & CBS 407.62 & $\mathrm{~N}$ \\
\hline H. papillosa (Fr.:Fr.) J. Erikss. & CBS 409.62 & $\mathrm{~N}$ \\
\hline H. quercina (Fr.:Fr.) J. Erikss. & CBS 340.29 & $\mathrm{~N}$ \\
\hline H. sambuci (Pers.) J. Erikss. & CBS 145.76 & $\mathrm{~N}$ \\
\hline H. setulosa (Berk. \& Curt.) Maas. & CBS 581.74 & $\mathrm{~N}$ \\
\hline H. subglobosa $\mathrm{Wu}$ & Wu $890805-2$ & $\mathrm{~N}$ \\
\hline Phanerochaete brunnea $\mathrm{Wu}$ & Wu 910808-9 & $\mathrm{N}$ \\
\hline P. himalayensis (Dhingra) Wu & Wu $880909-73$ & $\mathrm{~N}$ \\
\hline P. leptoderma $\mathrm{Wu}$ & Wu 910725-34 & $\mathrm{N}$ \\
\hline Phlebia formosana $\mathrm{Wu}$ & Wu $880817-14$ & $\mathrm{~N}$ \\
\hline \multirow{2}{*}{\multicolumn{3}{|c|}{ Pulcherricium caeruleum (Schrad.:Fr.) }} \\
\hline & & \\
\hline Parm. & Wu 880803-1 & $\mathrm{N}$ \\
\hline \multicolumn{3}{|l|}{ Resinicium bicolor (Alb. \& Schw,:Fr.) } \\
\hline Parm. & CBS 158.65 & $\mathrm{~N}$ \\
\hline R. bicolor (Alb. \& Schw,:Fr.) Parm. & Wu $880804-13$ & $\mathrm{~N}$ \\
\hline R. furfuraceum (Bres.) Parm. & CBS 637.78 & $\mathrm{~N}$ \\
\hline
\end{tabular}

${ }^{a}$ Sources of isolates: Wu (the National Museum of Natural Science, Taichung, Taiwan); USDA (U.S. Department of Agriculture-Forest Service, Forest Products Laboratory, Madison, WI); DAOM (Ottawa Central Experimental Farms, Canada); IFO (Osaka Institute of Fermentation, Japan); CBS (Centraalbureau voor Schimmelcultures, Baarn, Netherlands); PPH (Plant Pathology Herbarium, National Taiwan University, Taipei, Taiwan).

${ }^{\mathrm{b}} \mathrm{C}=$ nematodes captured, infected, and consumed; $\mathrm{N}=$ no effect; $\mathrm{T}$ $=$ neither captured nor infected, but poisoned and killed after ingestion of hyphal contents. ber 1991 and May 1992. For comparative study, approximately 200 Aphelenchoides were added to the nongerminated or germinated basidiospores of Hyphoderma macronatum, collected from its natural habitat, to test the nematode-infecting capability of the fungus on $3 \%$ water agar plates.

Ultrastructural host-parasite interactions. Characteristics of the host-parasite interactions were studied with previously published methods (29). Host-parasite interactions in areas of colonies that were intensively occupied by nematodes were examined with a stereomicroscope. Agar disks from these areas were sampled, fixed with glutaraldehyde and osmium tetroxide, and processed for transmission and scanning electron microscopy.

\section{RESULTS}

Mode of parasitism. Of the 51 species of resupinate basidiomycetous fungi tested, 18 Hyphoderma spp. were shown to be nematophagous on Aphelenchoides spp. (Table 1). The 18 Hyphoderma spp. could be divided into two types based on mode of parasitism. One type consisted of seven species, i.e., $\mathrm{H}$. baculorubrense, $H$. guttuliferum, $H$. macronatum, $H$. praetermissum, $H$. puberum, $H$. rude, and $H$. tenue, which captured and infected nematodes with adhesive one- or two-celled, smooth or roughened stephanocysts on a stalk or hyphae (Fig. 1A-C). Stephanocysts could attack at any point over the cuticle of the nematode, but attachment to the head or tail region was most common. Stephanocysts usually were not deciduous, particularly for the one-celled type (Fig. 1B), with some exceptions. In some species, such as H. macronatum and a Hyphoderma sp. (NP1), stephanocysts, especially young ones, were easily broken from the subtending hypha by the escaping nematodes and dispersed to new locations (Fig. 1C). In these instances, the Hyphoderma sp. was considered parasitic rather than predacious. Ultra-thin sections of the stephanocysts revealed a dolipore-parenthesome septum (Fig. 1D) typical of basidiomycetous fungi. Stephanocyst surfaces were covered with extensive fibrous, electron-dense mucilage (Fig. 1E). Numerous vesicles often were present at the periphery of the stephanocysts and frequently were associated with the endoplasmic reticulum (Fig. 1F). After stephanocysts had been attached to the cuticle of the host for at least $2 \mathrm{~h}$, much more mucilage was secreted. The mucilage at the host-parasite interface became increasingly pronounced and pad-shaped (Figs. 1C, 2A-C), which apparently aided the capture. Meanwhile, short protuberances from stephanocysts pressed against and slightly indented the nematode cuticle (Fig. 2A). Subsequently, an infection peg from the protuberance penetrated the host (Fig. 2B and C). A distinct electron-dense apposition surrounding the infection peg formed beneath the nematode cuticle and may have been a defense mechanism (Fig. 2B and C). Damage and deterioration of muscle and organelles caused by the penetration and infection were noticeable (Fig. 2C). Profuse trophic hyphae consumed the body contents and broke out to generate a new crop of stephanocysts (Fig. 2D).

Of the 57 isolates representative of the Corticiaceae and Stereaceae collected from Taiwan, only two isolates produced stephanocysts and captured nematodes. These two isolates were identified as Hyphoderma macronatum based on the characteristic mucronate cystidia. A fresh $H$. macronatum fruiting body discharged abundant basidiospores, adequate to test for nematophagous capacity. These basidiospores did not adhere to nematodes or infect them directly. Nevertheless, when the basidiospores germinated, they developed stephanocysts that exhibited typical nematophagous characteristics (Fig. 3A).

The second type of nematode parasitism was exhibited by $H$. albicans, $H$. amoenum, $H$. heterocystidium, $H$. medioburiensis, $H$. mutatum, $H$. obtusiforme, $H$. pallidum, $H$. populneum, $H$. radula, $H$. setigerum, $H$. typhicola, and a species of tentatively identified Hyphoderma in our collection. These isolates did not produce stephanocysts or capture nematodes. They did, however, attack and consume them by a completely different method. The cytoplasmic contents of these Hyphoderma spp. apparently were toxic in varying degrees to mycophagous nematodes such as 

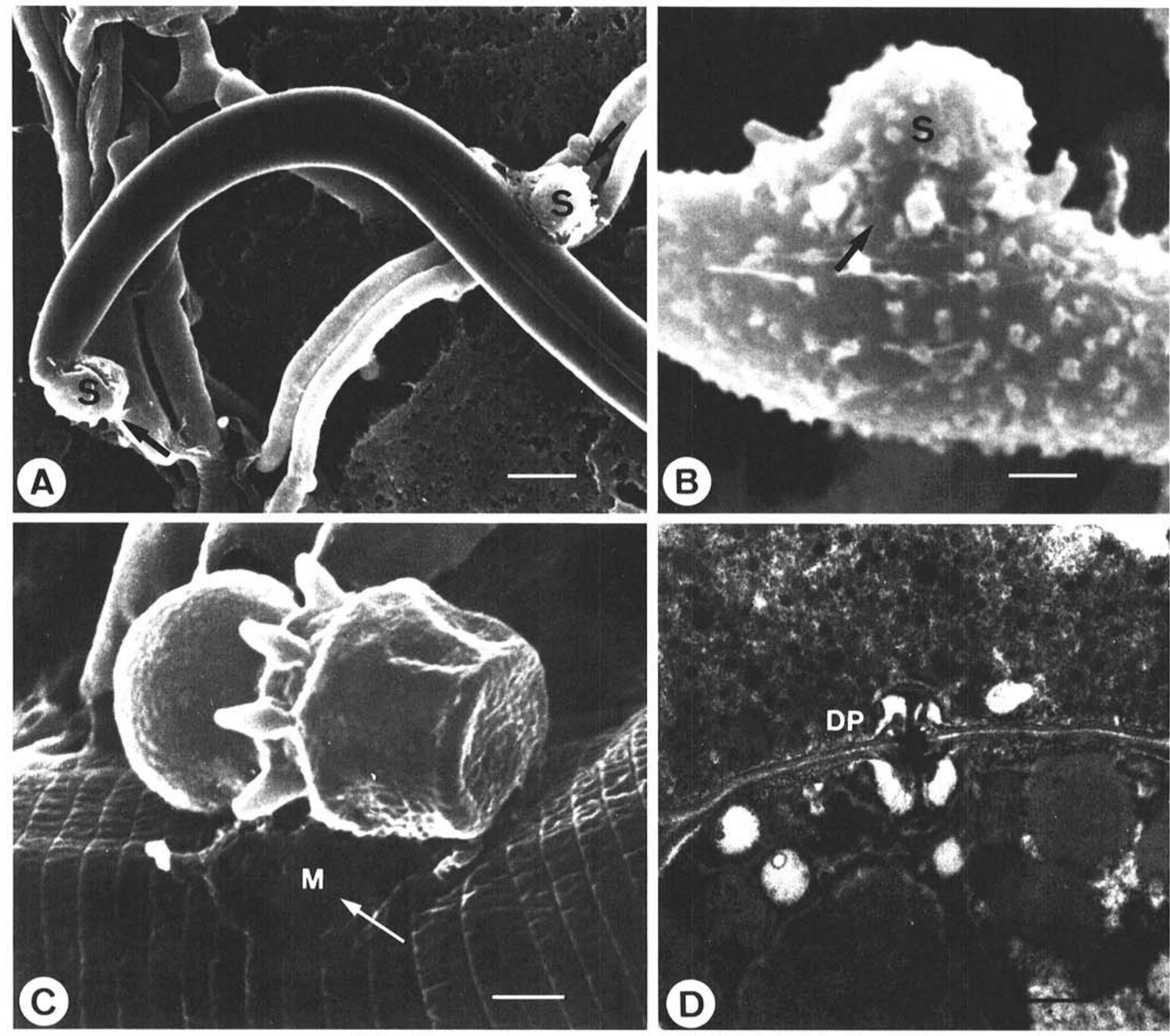

$$
\ln ^{2}+\infty
$$

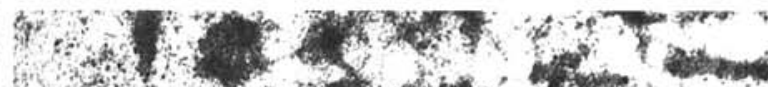
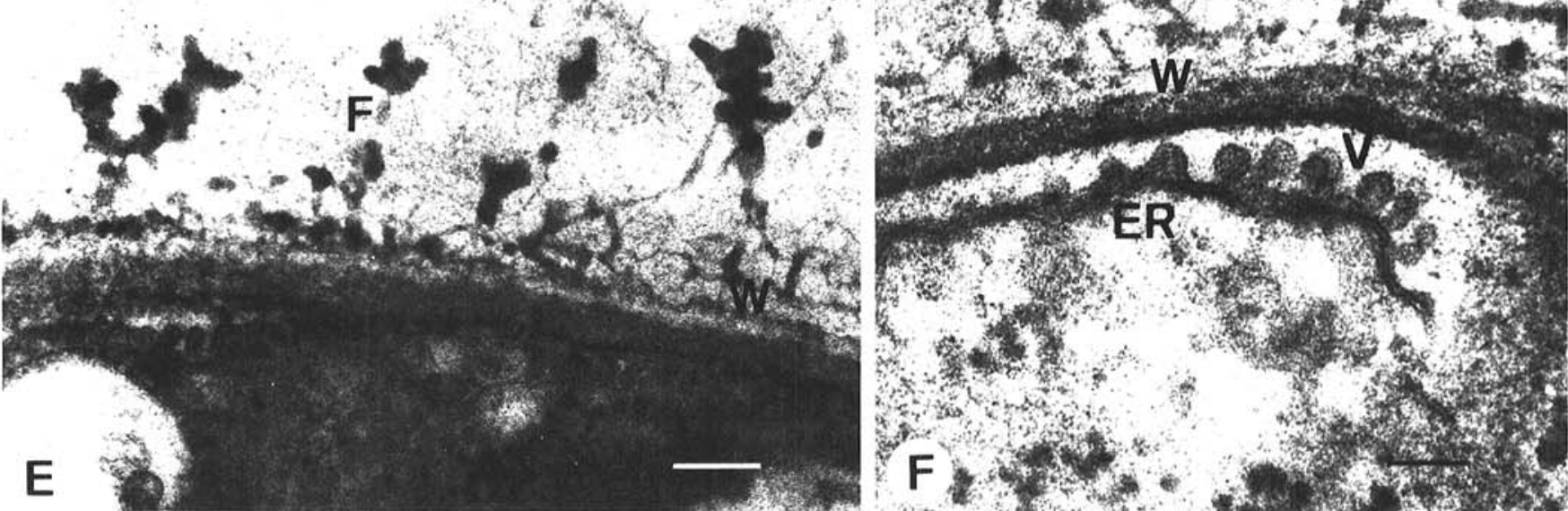

Fig. 1. A, Stephanocysts (S) of Hyphoderma praetermissum adhering to an individual Aphelenchoides sp. at the head and body regions (arrows). Bar $=5 \mu \mathrm{m}$. B, H. puberum producing one-celled, roughened, adhesive stephanocysts with a ring of spines at the base (arrow). Bar $=1 \mu \mathrm{m}$. C, A two-celled stephanocyst of a Hyphoderma sp. (NP1) adhering to the nematode by adhesive mucilage (M) of fungal origin. Bar $=1 \mu \mathrm{m}$. D, Septa of the stephanocysts of Hyphoderma sp. NP1 with dolipore and parenthesome structures (DP). Bar $=0.3 \mu \mathrm{m}$. E, Fimbriate, electrondense substances (F) coating the wall surface (W) of a stephanocyst. Bar $=0.1 \mu \mathrm{m}$. F, Numerous minute vesicles (V) at the periphery of a stephanocyst, juxtaposed with endoplasmic reticulum (ER). Bar $=0.05 \mu \mathrm{m}$. 
Aphelenchoides or Bursaphelenchus but not to free-living nematodes such as Rhabditis or Plectus. Mycophagous nematodes ingested the hyphal contents, became feeble and sluggish, and died within $2 \mathrm{~h}$. The fungi then developed short, stout, lateral branches that grew toward and coiled around the nematodes (Fig. 3B and C) and randomly penetrated the body. The assimilative hyphae filled the body cavity and consumed the contents within $24 \mathrm{~h}$, leaving a thin layer of cuticle (Fig. 3D).

The remaining Hyphoderma spp. and other related genera in the Corticiaceae (Hyphodontia, Phanerochaete, etc.) had no apparent effect on nematodes (Table 1).

Host range and preference of Hyphoderma spp. To determine the differential nematode host range and relative specificity, $H y$ phoderma sp. NP1 and several nematode species were chosen as experimental models. The choice of Hyphoderma sp. NP1 was because of the easy removal of the stephanocysts by the nematodes. Thus, the parasite could easily gain access to the nematode to attack and infect it. Stephanocysts adhered to $A$. besseyi and B. xylophilus and attacked these nematodes. Stephanocysts adhered to and infected soil-inhabiting nematodes such as
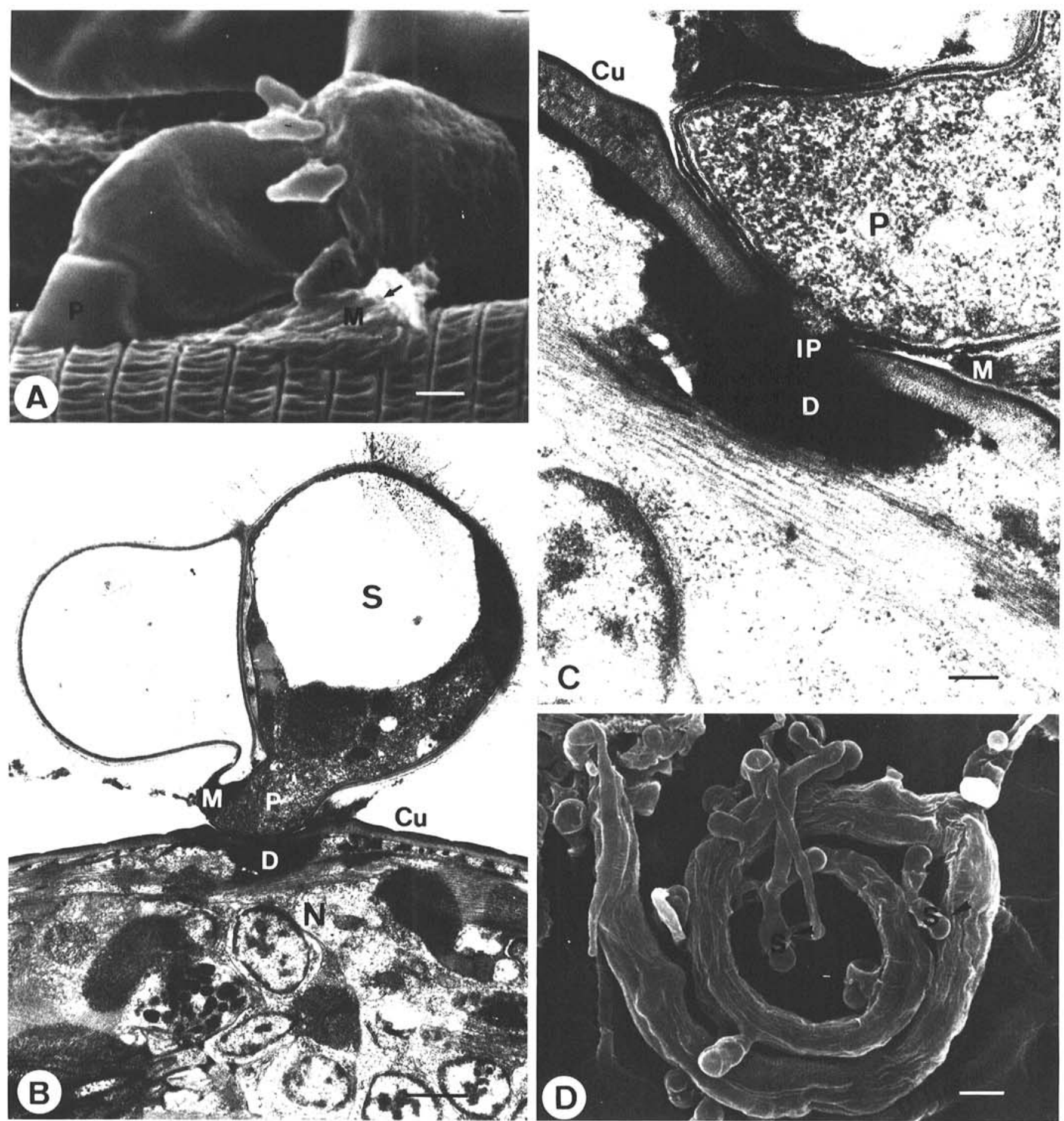

Fig. 2. A, Short protuberance (P) from stephanocyst cell of a Hyphoderma sp. (NP1) attached to a nematode's cuticle. Note the presence of padlike mucilage (M) (arrow) at the interface. Bar $=0.5 \mu \mathrm{m}$. B, A two-celled stephanocyst (S) attached to the indented cuticle (Cu) of an Aphelenchoides nematode $(\mathrm{N})$; one cell is empty, and the other cell has produced a short protuberance and an incipient infection peg to penetrate the host. An electron-dense deposit (D) secreted by the host surrounds the peg of the parasite. Bar $=1 \mu \mathrm{m}$. C, An enlargement of a portion of Fig. $2 \mathrm{~B}$. IP $=$ incipient infection peg. Bar $=0.2 \mu \mathrm{m}$. D, Trophic hyphae of Hyphoderma sp. breaking through the integument of the nematode and forming new stephanocysts (arrows). Bar $=5 \mu \mathrm{m}$. 
Trophorus sp. and Rotylenchulus sp. Although stephanocysts readily adhered to Helicotylenchus, no infection took place. Stephanocysts did not adhere to the rice root lesion nematode, Hirschmanniella oryzae nor to the free-living nematodes, such as Rhabditis sp. and Plectus sp. (Table 2).

\section{DISCUSSION}

This is the first report in which species of Hyphoderma, which are nongilled resupinate basidiomycetous fungi, were shown to capture or poison and consume nematodes. The mode of trapping and infecting nematodes by $H$. baculorubrense, $H$. guttuliferum, $H$. macronatum, $H$. praetermissum, $H$. puberum, $H$. rude, and $H$. tenue (i.e., production of stephanocysts) is comparable to the mode of gilled fungi, Hohenbuehelia or Resupinatus, that capture or infect nematodes by adhesive hourglass-shaped cells initiated on the hyphae or conidia $(2,27,28)$. Likewise, the poisoning of nematodes by the unknown component in hyphae of $H$. albicans, $H$. amoenum, $H$. heterocystidium, $H$. medioburiensis, $H$. mutatum, $H$. obtusiforme, $H$. pallidum, $H$. populneum, $H$. radula, $H$. setigerum, and $H$. typhicola is similar to that of the gilled mushroom, Pleurotus spp. $(2,27,28)$. The toxic substances that account for the death of the nematodes are unknown and deserve further exploration, as they may be a good sources for novel bionematicides or suggest molecular structures for synthetic nematicides. The evidence hints at the convergent evolution of some litter- or wood-inhabiting basidiomycetous fungi. Our results support the viewpoint that the ability of such nongilled or gilled
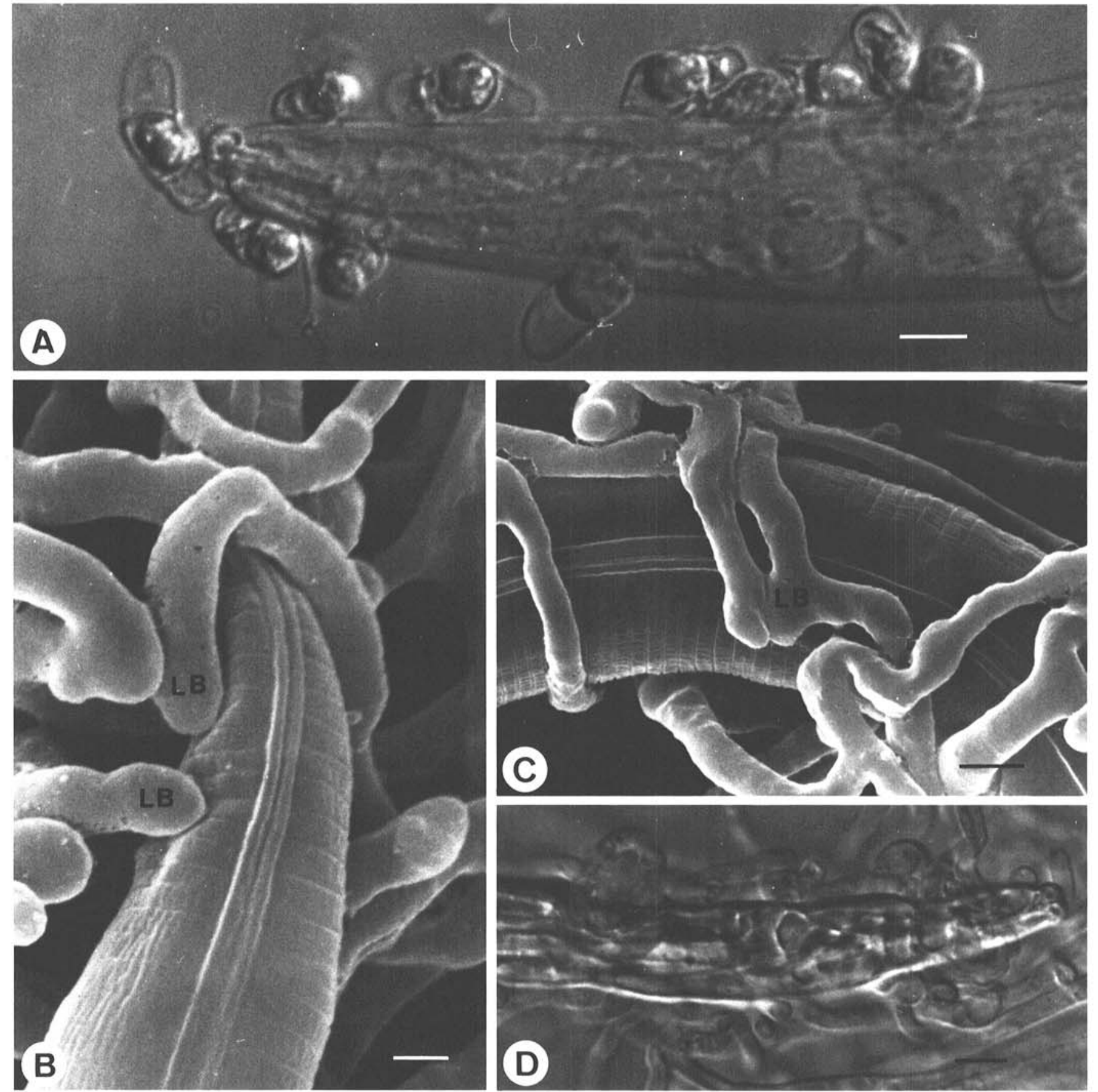

Fig. 3. A, Basidiospores of stephanocysts germinated and developed from Hyphoderma macronatum and attached to the cephalic region of the nematode host. Bar $=5 \mu \mathrm{m}$. B, Short, stout, lateral branches (LB) of $H$. mutatum contacting and slightly indenting the cuticle of a poisoned nematode. Bar $=1 \mu \mathrm{m}$. C, Lateral branches of $\mathrm{H}$. mutatum contacting or coiling around the poisoned nematode. Bar $=2 \mu \mathrm{m}$. D, A mycophagous nematode, Aphelenchoides sp., poisoned, penetrated, and consumed by $H$. mutatum. The dead nematode is filled with assimilative hyphae within 24 h. Bar $=1 \mu \mathrm{m}$. 
fungi to feed on nematodes may assist them to survive or thrive in nitrogen-restricted niches similar to those of carnivorous higher plants $(2,17,27,28)$.

Occasionally, fimbriate substances were seen in transmission electron micrographs extending from the stephanocyst plasmalemma to the outer wall. No direct evidence indicates that these peripheral vesicular structures are derived from endoplasmic reticulum and transmit the fimbriate substances, but the possibility cannot be eliminated. In the periphery of the adhesive knob of a Dactylella sp. and in the adhesive columnar processes of Monacrosporium cionopagum (Drech.) Subram., similar vesicles have been observed (30). Exocytosis of the contents of peripheral vesicles may be a mechanism responsible for the adhesion of encysted zoospores of Phytophthora cinnamomi Rands to the host root surface (15). The attachment and infection of nematodes by stephanocysts of Hyphoderma sp. NP1 are similar to the activities of Drechmeria (Meria) coniospora Gams \& Jansson (13). Both of these nematophagous fungi require enzymatic and mechanical force to penetrate the host. However, the radiate structure of the adhesive layer coating the adhesive bud in conidia of $D$. coniospora differed markedly from the fimbriate mucilage coating on the stephanocysts of Hyphoderma sp. $(6,25)$. The nature of these adhesives merits further investigation.

Hyphoderma tenue (CBS 280.50), in contrast to the strain from Ottawa (DAOM 22985), did not produce stephanocysts and had no nematode-infecting capacity. Hyphoderma argillaceum (CBS 250.73) produced sparse, nonfunctional stephanocysts. The loss of ability to form stephanocysts or the formation of nonfunctional stephanocysts may be caused by long-term storage of the isolate, which can cause physiological changes such as loss of pathogenicity or sporulation capacity (14).

Because of different nematode host ranges and specificity, the application of these Hyphoderma spp. to biocontrol of plantparasitic nematodes will be limited to certain genera or species. The mechanisms responsible for the differential recognition, adhesion, and infection of nematodes by Hyphoderma are unknown and merit further study. This has already been clarified for some other trapping or endoparasitic fungi (18-20,24). For instance, Drechmeria coniospora can adhere to the cephalic region and tail of Caenorhabditis elegans (Maupas) Dougherty, Anguina tritici (Steinbuch) Filipjev, and Meloidogyne incognita, but it cannot adhere to the cuticle of Xiphinema americanum Cobb or Bursaphelenchus xylophilus. The host specificity of $D$. coniospora may be related to the sialic acid on the cuticle of certain nematodes, which acts as a receptor that is recognized and bound by the lectin coating on the spores of the fungus (11).

TABLE 2. Differential response of nematodes to the attachment and infection by stephanocysts of a Hyphoderma sp. (NP1)

\begin{tabular}{|c|c|c|}
\hline \multirow[b]{2}{*}{ Nematode } & \multicolumn{2}{|c|}{ Stephanocysts ${ }^{a}$} \\
\hline & Attachment & Infection \\
\hline \multicolumn{3}{|l|}{ Bud, leaf, and stem nematodes } \\
\hline Aphelenchoides sp. & A & I \\
\hline A. besseyi Christie & A & I \\
\hline Bursaphelenchus xylophilus & & \\
\hline (Steiner \& Buhrer) Nickle & A & I \\
\hline \multicolumn{3}{|l|}{ Soil-inhabiting nematodes } \\
\hline $\begin{array}{l}\text { Helicotylenchus sp. } \\
\text { Hirschmanniella oryzae }\end{array}$ & A & $\mathrm{N}$ \\
\hline (van Breda de Haan) Luc \& Goodey & $\mathrm{N}$ & $\mathrm{N}$ \\
\hline Meloidogyne incognita & & \\
\hline (Kofold \& White) Chitwood & $\mathrm{N}$ & $\mathrm{N}$ \\
\hline Rotylenchulus sp. & A & I \\
\hline Trophurus sp. & A & I \\
\hline Xiphinema sp. & $\mathrm{N}$ & $\mathrm{N}$ \\
\hline \multicolumn{3}{|l|}{ Free-living and carnivorous nematodes } \\
\hline Mononchus sp. & $\mathrm{N}$ & $\mathrm{N}$ \\
\hline Plectus sp. & $\mathrm{N}$ & $\mathrm{N}$ \\
\hline Rhabditis sp. & $\mathrm{N}$ & $\mathrm{N}$ \\
\hline
\end{tabular}

$\overline{{ }^{a} \mathrm{~A}=\text { Attachment to nematode, } \mathrm{I}=\text { nematode infected, } \mathrm{N}=\text { no attachment }}$ or infection.
We predict that other gilled or nongilled basidiomycetous fungi with the capacity of trapping, infecting, poisoning, and consuming nematodes or microfauna will be discovered. These characteristics probably are a selective advantage that permit the fungi to colonize and persist in nutritionally competitive environments.

\section{LITERATURE CITED}

1. Barron, G. L., and Dierkes, Y. 1977. Nematophagous fungi: Hohenbuehelia, the perfect state of Nematoctonus. Can. J. Bot. 55:3054-3062.

2. Barron, G. L., and Thorn, R. G. 1987. Destruction of nematodes by species of Pleurotus. Can. J. Bot. 65:774-778.

3. Boidin, J. 1950. Sur l'existence de races interstériles chez Gloeocystidium tenue (Pat.): Étude morphologique et comportment nucléaire de leurs cultures. Bull. Soc. Mycol. Fr. 66:204-221.

4. Boidin, J. 1958. Essai biotaxonomique sur les hydnes resupines et les corticines. Rev. Mycol. 6:1-338.

5. Burdsall, H. H., Jr. 1969. Stephanocysts: Unique structures in the Basidiomycetes. Mycologia 61:915-923.

6. Dijksterhuis, J., Veenhuis, M., and Harder, W. 1990. Ultrastructural study of adhesion and initial stages of infection of nematodes by conidia of Drechmeria coniospora. Mycol. Res. 94:1-8.

7. Drechsler, C. 1941. Some Hyphomycetes parasitic on free-living terricolous nematodes. Phytopathology 31:773-802.

8. Drechsler, C. 1943. Two new basidiomycetous fungi parasitic on nematodes. J. Wash. Acad. Sci. 33:183-189.

9. Drechsler, C. 1946. A clamp-bearing fungus parasitic and predacious on nematodes. Mycologia 38:1-23.

10. Drechsler, C. 1949. A nematode-capturing fungus with anastomosing clamp-bearing hyphae. Mycologia 41:369-387.

11. Drechsler, C. 1954. A nematode-capturing fungus with clampconnections and curved conidia. J. Wash. Acad. Sci. 44:82-85.

12. Eriksson, J., and Ryvarden, L. 1976. The Corticiaceae of North Europe. Fungiflora, Oslo.

13. Gams, W., and Jansson, H. B. 1985. The nematode parasite Meria coniospora Drechsler in pure culture and its classification. Mycotaxon 22:33-38.

14. Griffin, D. H. 1981. Fungal Physiology. John Wiley \& Sons, New York.

15. Gubler, F., and Hardham, A. R. 1988. Secretion of adhesive material during encystment of Phytophthora cinnamomi zoospores, characterized by immunogold labelling with monoclonal antibodies to components of peripheral vesicles. J. Cell Sci. 90:225-235.

16. Hallenberg, N. 1990. Ultrastructure of stephanocysts and basidiospores in Hyphoderma praetermissum. Mycol. Res. 94:1090-1095.

17. Helsop-Harrison, Y. 1978. Carnivorous plants. Sci. Am. 238:104-115.

18. Jansson, H. B., Jeyaprakash, A., and Zuckerman, B. M. 1985. Differential adhesion and infection of nematodes by the endoparasitic fungus Meria coniospora (Deuteromycetes). Appl. Environ. Microbiol. 49:552-555.

19. Jansson, H. B., and Nordbring-Hertz, B. 1983. The endoparasitic nematophagous fungus Meria coniospora infects nematodes specifically at the chemosensory organs. J. Gen. Microbiol. 129:1121-1126.

20. Jansson, H. B., and Nordbring-Hertz, B. 1984. Involvement of sialic acid in nematode chemotaxis and infection by an endoparasitic nematophagous fungus. J. Gen. Microbiol. 130:39-43.

21. Jülich, W. 1976. Studies in resupinate Basidiomycetes. IV. Persoonia $8: 431-442$

22. Kendrick, B., and Watling, R. 1979. Mitospores in Basidiomycetes. Pages 473-545 in: The Whole Fungus. B. Kendrick, ed. National Museum of Natural Sciences, Ottawa.

23. Liou, J. Y., and Tzean, S. S. 1992. Stephanocysts as nematodetrapping and infecting propagules. Mycologia 84:786-790.

24. Nordbring-Hertz, B., and Mattiasson, B. 1979. Action of a nematodetrapping fungus shows lectin-mediated host-microorganism interaction. Nature 281:477-479.

25. Saikawa, M. 1982. An electron microscope study of Meria coniospora, an endozoic nematophagous Hyphomycete. Can. J. Bot. 60:2019-2023.

26. Southey, F. F. 1970. Laboratory Methods for Plant and Soil Nematodes. Her Majesty's Stationery Office, London.

27. Thorn, R. G., and Barron, G. L. 1984. Carnivorous mushrooms. Science 224:76-78.

28. Thorn, R. G., and Barron, G. L. 1986. Nematoctonus and the tribe Resupinateae in Ontario, Canada. Mycotaxon 25:321-453.

29. Tzean, S. S., and Estey, R. H. 1978. Schizophyllum commune Fr. as a destructive mycoparasite. Can. J. Microbiol. 24:780-784.

30. Tzean, S. S., and Estey, R. H. 1979. Transmission electron microscopy of fungal namatode-trapping devices. Can. J. Plant Sci. 59:785-795. 